\title{
Plant-Derived Antioxidants Protect the Nervous System From Aging by Inhibiting Oxidative Stress
}

\author{
Xiaoji Cui, Qinlu Lin and Ying Liang* \\ Molecular Nutrition Branch, National Engineering Laboratory for Rice and By-product Deep Processing, College of Food \\ Science and Engineering, Central South University of Forestry and Technology, Changsha, China
}

Alzheimer's disease (AD) has become a major disease contributing to human death and is thought to be closely related to the aging process. The rich antioxidant substances in plants have been shown to play a role in delaying aging, and in recent years, significant research has focused on also examining their potential role in AD onset and progression. Many plant-derived antioxidant research studies have provided insights for the future treatment and prevention of $\mathrm{AD}$. This article reviews various types of plant-derived antioxidants with anti-aging effects on neurons. Also it distinguishes the different types of active substances that exhibit different degrees of protection for the nervous system and summarizes the mechanism thereof. Plant-derived antioxidants with neuroprotective functions can protect various components of the nervous system in a variety of ways and can have a positive impact on interventions to prevent and alleviate AD. Furthermore, when considering neuroprotective agents, glial cells also contribute to the defense of the nervous system and should not be ignored.

\section{OPEN ACCESS}

Edited by:

Rubem C. A. Guedes, Federal University of Pernambuco,

Brazil

Reviewed by: Ghulam Md Ashraf, King Abdulaziz University, Saudi Arabia Isabel Iriepa, University of Alcalá, Spain

*Correspondence: Ying Liang

liangying498@163.com

Received: 10 February 2020 Accepted: 15 June 2020

Published: 14 July 2020

Citation:

Cui X, Lin Q and Liang Y (2020) Plant-Derived Antioxidants Protect the Nervous System From Aging by Inhibiting Oxidative Stress. Front. Aging Neurosci. 12:209. doi: 10.3389/fnagi.2020.00209
Keywords: plant-derived antioxidants, nerve aging, neuroprotection, nerve cells, nervous system

\section{INTRODUCTION}

Plants have developed a wide variety of active substances, including many antioxidants, to adapt to their constantly evolving environment. Accumulating evidence shows that some antioxidants in plants can effectively scavenge free radicals, protect cells, delay aging, and prevent diseases related to aging (Hassan et al., 2017). At present, three major diseases, including cancer, cardiovascular disease, and Alzheimer's disease (AD), are closely related to the aging of individuals. In particular, $\mathrm{AD}$ is closely related to the pathological changes of nerve cells that manifest and persist across the human lifetime. Such neuronal changes, or lesions, are characterized by tangles of nerve fibers and the increased presence of $\beta$-amyloid and hyperphosphorylated tau in the brain, which ultimately leads to a decline in nervous system function. Since there is no effective treatment for AD in modern medicine, and since the prevalence of AD is positively correlated with an individual's age, the risk of $\mathrm{AD}$ can be effectively reduced by delaying or mitigating the negative effects on the nervous system that are associated with the aging process (Goedert, 2015). As the main source of antioxidants in humans, plants play an important role in the anti-aging process of the human body. At present, the use of plant-derived antioxidants to reduce the damage caused by oxidative stress to nerve cells has been well documented. Accordingly, various types of nerve cells strategically coordinate functions to contribute to the collective well-being of the nervous system. Therefore, the function of plant antioxidants applies not only to protecting nerve cells but also to protecting the entire nervous system of the body. This article reviews the role of various antioxidants on AD progression and describes the mechanistic role of such substances on the nervous system. 


\section{THE PROTECTIVE EFFECT OF PLANT-DERIVED ANTIOXIDANTS ON NERVE CELLS}

Plants contain a wide variety of antioxidants that resist various naturally occurring environmental threats and which are metabolized primarily during aerobic activities. Free radicals become oxidized when they combine with oxygencontaining substances and can damage the host organism by stealing surrounding electrons (Wojtunik-Kulesza et al., 2016). Antioxidants in plants can prevent the damage caused by free radicals (Liochev, 2013) by preventing electron transfer. Free radicals in the human body that are not cleared fast enough can damage cells and eventually lead to local apoptosis and in turn global aging of the body. For cells in the nervous system, degenerative diseases that affect neurons and nerve bundles are related to the damage caused by oxidative free radicals. The ability of plant-derived antioxidants to scavenge free radicals can reduce the damage of nerve cells caused by oxidative stress and help maintain a more active physiological state. In addition, plant-derived antioxidant substances have a wide range of cell types that aid in the removal of nerve cell free radicals and can effectively protect most of the nervous system. Antioxidants such as polyphenols, vitamins, alkaloids, polysaccharides, and active peptides (Figure 1) help to maintain the structure and function of neurons and prolong their healthy state (Del Rio, 2015). In subsequent sections, we will briefly review each of these substances and how they protect the brain and nerve cells against the damaging effects of aging.

\section{Polyphenols}

Polyphenols are the most abundant antioxidant in plants and have an excellent ability to capture oxidative free radicals (Jiang et al., 2016). Polyphenols can be sub-classified into flavonoids, phenolic acids, and tannins depending on their physical structure.

\section{Flavonoids}

Flavonoids can be isolated from vegetables, fruits, and rice. This class of polyphenols have a lower redox potential than oxygen and superoxide radicals, making these antioxidants better suited to bind active oxygen (Duthie and Crozier, 2000). Recent studies have shown that flavonoids can be absorbed into the blood and tissue through the intestine and can easily reach the brain through the blood-brain barrier. Once in the brain, flavonoids and their metabolites protect the cells inside from oxidative stress (Pietta, 2000). These flavonoids can also induce glial cell secretion of nerve growth factor to prevent the degradation of dopaminergic neurons in the substantia nigra (Jaeger et al., 2018). In an exemplary study, Zhao et al. (2013) found that one specific flavonoid called apigenin protects the extracellular environment in the nervous system (Jung and Kim, 2018) by scavenging free radicals through the release of antiamyloid proteins. This study also found that flavonoids can protect neurons from axonal degradation, myelin rupture (Zhao et al., 2013), trans-differentiation, and Schwann cell proliferation
("Correction: Curcumin and Apigenin - novel and promising therapeutics against chronic neuroinflammation in Alzheimer's disease," No author, 2015) through the Krox20 pathway and extracellular signal-regulated kinase-independent processes. In another experiment, the hesperidin flavonoid activated the secretion of superoxide dismutase and glutathione (Jeong et al., 2019) in the mouse brain. Hesperidin (Matias et al., 2017), rutin (El-Sayed el et al., 2008), and rhamno (Omar et al., 2017) can reduce the amount of free $\mathrm{Ca}^{2+}$ located between brain cells when fighting against neurogenic excitotoxicity and can attenuate the decrease of the mitochondrial membrane potential and increase caspase- 3 activity (Lutz et al., 2015). In addition, recent studies have shown that treating neurons in the cerebral cortex with microglial cells cultured with agathisflavone may protect them from oxidative stress by modulating estrogen signaling. Agathisflavone has been found to significantly increase the number of neuronal progenitor cells and mature neurons without increasing astrocytes or microglia, and also to effectively reduce the inflammatory factors factor- $\alpha$, interleukin-6, interleukin-1 $\beta$, NO, and PGE2 (Bakhtiari et al., 2017). Other studies have shown that agathisflavone, which regulates estrogen signaling, stimulates neuronal production in vitro and enhances the neuroprotective properties of microglia and astrocytes.

\section{Phenolic Acids}

Phenolic acid refers to a compound having several phenolic hydroxyl groups on the same benzene ring and is an allelochemical substance that regulates the growth state of plants through the process of allelopathy. The antioxidant activity of phenolic acids in organisms is easily affected by environmental influences and often includes an oxidative effect under the action of $\mathrm{Cu}^{2+}$.

Ferulic acid is a ubiquitous phenolic acid found in the leaves and seeds of plants. The conjugated structure of the ferulic acid molecule can form a relatively stable phenoxy radical in ultraviolet light to terminate the free radical chain reaction (Dos Santos Souza et al., 2018). Ferulic acid protects neurons from oxidative stress by inhibiting the activation of p38 MAPK, caspase-3, and COX-2 (Graf, 1992), and by downregulating damage caused by the MEK/ERK/p90RSK signaling pathway (Lin et al., 2015). In mice, it was found that ferulic acid can increase SOD, CAT, and GSH-Px activity in the brains of depressed mice and reduce TBA-RS levels in the blood, hippocampus, and cerebral cortex (Lin et al., 2015). Additionally, ferulic acid can significantly reduce seizure intensity, myoclonic spasms, and cognitive decline in epileptic mice (Lenzi et al., 2015), and can reduce the $\mathrm{Bax} / \mathrm{Bcl} 2$ ratio in dopaminergic neurons in the striatum in mice with Parkinson's disease (PD) (Hassanzadeh et al., 2017). Furthermore, ferulic acid treatment in a mouse model of neuroinhibition reduces $\mathrm{p}$-JNK, $\mathrm{p}$-NFKB in glial cells of the mouse hippocampus and activates mitochondrial apoptotic molecules (Bax, cytochrome c, caspase-3, and PARP1) in small/medium glial cells to induce anti-inflammatory effects by interfering with the TLR4/MD2 complex binding site (Nagarajan et al., 2015).

Another study using ellagic acid to treat oxygen-glucose deprivation and reoxygenation models of rat cortical neurons 


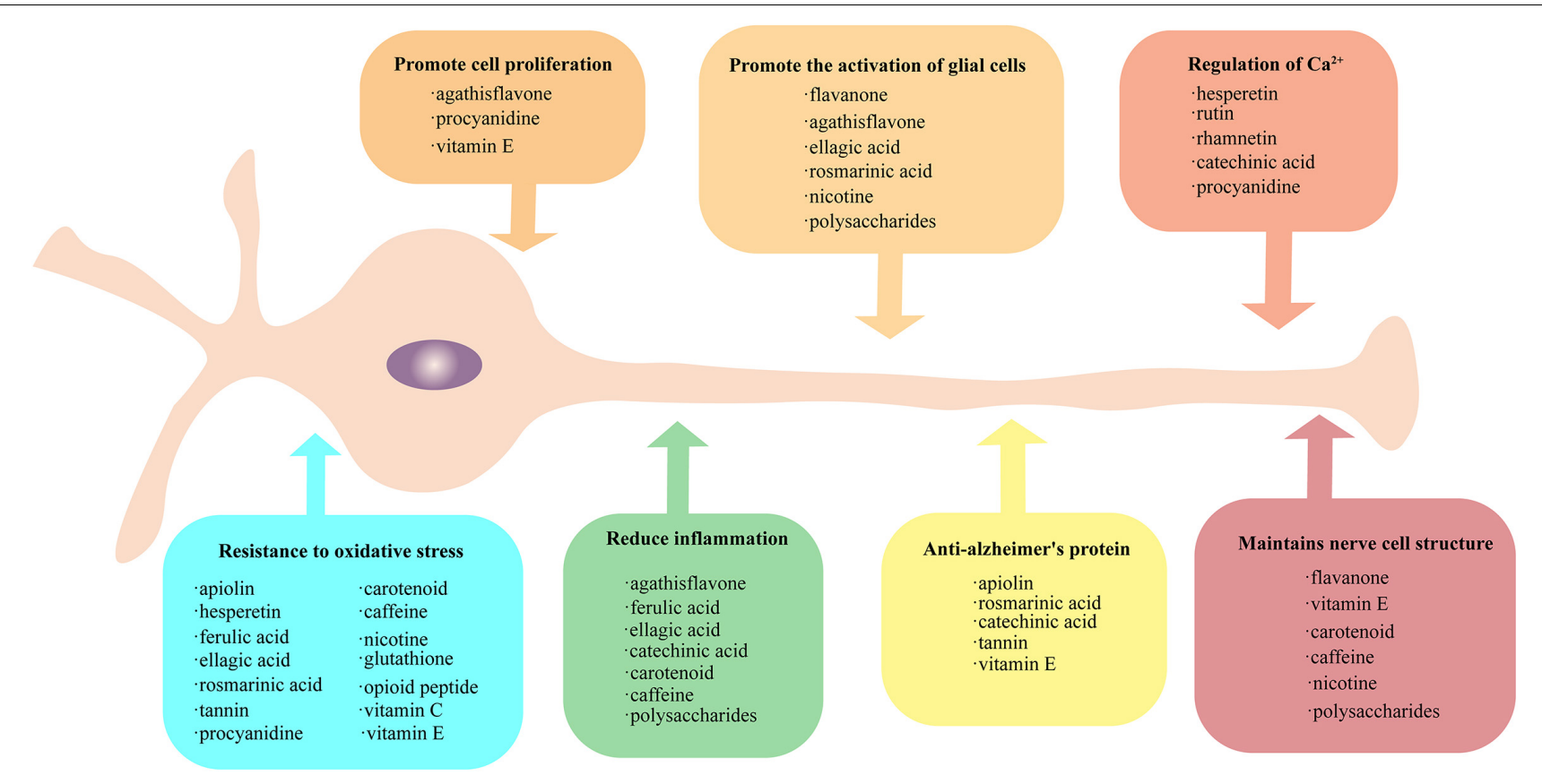

FIGURE 1 | Protective method of plant-derived active substances on nerves. Active plant substances exhibit rich neuroprotective methods, which can be grouped into seven categories: (1) promote the activation of glial cells, (2) promote cell proliferation, (3) regulation of Ca ${ }^{2+}$, (4) maintain nerve cell structure, (5) provide resistance to oxidative stress, (6) reduce inflammation, and (7) anti-Alzheimer's protein. The active substances falling into each of these seven categories are provide in the respective boxes. All the active substances could resist oxidative stress, and some substances have similar protection patterns.

cultured in vitro found a significantly reduced volume of cerebral infarction and improved neurological deficit score in rats by increasing the Bcl-2/Bax ratio (Rehman et al., 2019). Similarly, Wang et al. (2019) found that the antioxidant defense of ellagic acid can cause astrocyte proliferation, glial cell line-derived neurotrophic factor (GDNF) release, and Nrf2 activation (Liu et al., 2017). Ellagic acid has also been shown to increase the activity of GSH-Px and SOD and to decrease the level of MDA in the striatum of PD mice (Wang et al., 2019). Even more, ellagic acid has additionally been shown to increase monoamine oxidase B (MAO-B), nuclear factor (erythrocyte derivation 2), $\mathrm{Nrf2}$, and heme oxygenase 1 (HO-1) and reduce the loss of tyrosine hydroxylase $(\mathrm{TH})$-positive neurons in the substantia nigra pars compacta (SNC) (Sarkaki et al., 2016). In a rat model of arsenic-induced injury, the hippocampus was treated with ellagic acid, which was shown to regulate total ROS production, apoptosis markers, BAX and Bcl2, and inflammatory markers IL-1 $\beta, \mathrm{TNF} \alpha$, and INF $\gamma$. At the same time, ellagic acid also prevented the decrease of the mitochondrial membrane potential (Baluchnejadmojarad et al., 2017).

Yet another phenolic acid, rosmarinic acid, has been found to reduce the amount of reactive oxygen species and malondialdehyde, which in turn attenuates cellular oxidative stress and protects hydrogen peroxide-treated glial cells (Firdaus et al., 2018) by phosphorylating protein kinase B (Akt), Ser9 Glycogen synthase kinase-3 $\beta$ (GSK-3 $\beta$ ), and Fyn. Rosmarinic acid further regulates the activity of Nrf2 to protect PC12 cells from oxidative stress (Gao et al., 2005) induced by amyloid $\beta(\mathrm{A} \beta)$. This substance can also reduce the oxidative stress (Lee et al., 2008) on SH-SY5Y (human dopaminergic neuron cells) by controlling the upregulation of $\mathrm{Bax}$ and the downregulation of $\mathrm{Bcl}-2$, and reduce mitochondrial membrane potential by reducing reactive oxygen species. At the same time, rosmarinic acid promotes the upregulation of $\mathrm{TH}$ and brain-derived neurotrophic factor (BDNF) genes to alleviate the cytotoxicity of $\mathrm{H}_{2} \mathrm{O}_{2}$-induced N2A cells (Ghaffari et al., 2014). After cerebral ischemia/reperfusion in rats, rosmarinic acid was found to increase the phosphorylation of Akt1, decrease the phosphorylation of JK3, and decrease the expression of cleaved caspase-3 to protect hippocampal neurons in the brain (Zhang et al., 2017c). A rat AD model was established by injecting $\mathrm{A} \beta 4$ into the bilateral lateral ventricle of rats, which resulted in a decrease in acetylcholine content and acetylcholinesterase activity. Treatment with rosmarinic acid prevented the observed changes in the $A \beta$ group and in another study attenuated $A \beta$ staining and astrocyte activation and enhanced auditory abilities (Kantar Gok et al., 2018).

\section{Tannins}

Tannins are widely distributed in plants and usually refer to plant polyphenols with a relative molecular mass of 500-3000 u. The antioxidant ability of tannins is related to the position and binding mode of the phenolic hydroxyl groups. Nevertheless, the tannin-like antioxidant ability is significantly different across different sub-structures.

Catechin and its derivatives are the main functional components in tea and many studies have shown that the effects of catechin on mitochondria-related pathways can 
prevent neurodegeneration and delay the decline of brain function (Assuncao and Andrade, 2015). Catechin protects $\mathrm{A} \beta$ - and 6-OHDA-induced neuronal apoptosis by activating the protein kinase $\mathrm{C}$ (PKC) pathway and PI3K/AKT, which inhibits the MAPKs pathway (Chen et al., 2018). Specifically, epigallocatechin-3-gallate (EGCG) was found to enhance the clearance of $\mathrm{AD}$-associated phosphorylated tau species in neurons (Chesser et al., 2016) and to improve cell metabolism and reduce oxidative stress to protect motor neurons (Che et al., 2017). The use of EGCG and related phenolic compounds can also redirect the amyloid-forming aggregation pathway of transgenic Caenorhabditis elegans strains that express amplified ATX3 (amyloid) toward non-toxic aggregation and prevent calcium influx-mediated cytotoxicity of nerve cells (Visentin et al., 2017). When DOX has been used to induce memory deficits in Wistar rats, catechin treatment was able to reduce neuronal toxicity and improve cognitive performance in a timeand dose-dependent manner (Cheruku et al., 2018).

Tannin is the main enzyme involved in the production and deposition of $\mathrm{A} \beta$ peptide, which regulates $\beta$-secretase (BACE1) activity and is a natural inhibitor of protein expression. Tannin also destabilizes neurotoxic $\mathrm{A} \beta$ fibrils and inhibits in vitro aggregation of tau peptides (Braidy et al., 2017) and can also reduce $\mathrm{MDA}$-enhanced SOD activity and higher respiratory factor-1 (NRF-1) in ischemic rats.

Grapes and lotus roots contain a wide range of tannins, the main functional component of which is proanthocyanidin (PC). Song et al. (2019) first confirmed that treatment of glutamate with PCs induced HT22 cells to block the phosphorylation of MAPK, including ERK1/2 and p38. Lotus anthocyanins can also regulate the activation of the $\mathrm{Bcl}-2$ and $\mathrm{Bcl}-\mathrm{xl}$ proteins, the latter of which protects hippocampal neurons from damage in extremely low-frequency electromagnetic fields and increases in $\mathrm{Ca}^{2+}$ levels. Damage to mice by extremely low-frequency electromagnetic fields revealed that lotus root PCs can mediate calcium signals and double the activity of messenger systems through $\mathrm{Ca}^{2+}$, CaMK II/CREB, BDNF, and the DG/PKC/MAPK signaling pathways to reverse mouse hippocampal cell oxidative stress and BDNF levels. Additionally, behavioral changes in the 6-OHDA mouse model were reversed by the PI3K/Akt signaling pathway (Zhang et al., 2017a), and the reduced number of dopaminergic cells and the levels of dopamine and its metabolites DOPAC and HVA were restored (Datla et al., 2007) when treated with PCs.

\section{Vitamins}

Vitamins in the body have always been regarded as one of the most bioavailable nutrients. Some vitamins, such as vitamin C, vitamin E, and carotenoids, have strong antioxidant and neuroprotective effects and are commonly found in plants.

Vitamin C, also known as ascorbic acid, has four hydroxyl functional groups, two of which are enol hydroxyl groups. Therefore, vitamin $\mathrm{C}$ is easily oxidized and dehydrogenated, which makes it extremely reductive and therefore also a highly effective antioxidant. The vitamin C transporter SVCT2 (Berger et al., 2003) can be expressed in both neurons and glial cells, and can regenerate the myelin of neuronal cells (Rohr et al., 2017).
The regenerative function of vitamin $\mathrm{C}$ can further produce glial cells (Guo et al., 2018) and cells of the sciatic nerve (Li et al., 2019), but there is no evidence yet that such an effect extends to neurons. Vitamins have excellent neuroprotective effects against the oxidative stress induced by metal and nonmetals, and can protect against lead-induced neuronal apoptosis in rats (Ebrahimzadeh-Bideskan et al., 2016), aluminum-induced neuronal apoptosis in Nile perch (Khalil and Hussein, 2015), iron-induced oxidative stress in rat brain tissue (Ganie et al., 2014), and arsenic-related neurological damage in rats (Sarkozi et al., 2016). Specifically, the ability of vitamin $C$ to scavenge free radicals can reduce the degree of oxidative stress and increase the viability of nerve cells in the cerebral cortex and striatum (Ballaz and Rebec, 2019).

Vitamin E mainly differs from vitamin $C$ in the sense that it is fat-soluble. Vitamin $\mathrm{E}$ features hydroxyl hydrogen on a diacetyl alcohol ring, which produces a strong reduction effect on oxygen free radicals and effectively inhibits lipid peroxidation. Therefore, vitamin $\mathrm{E}$ can reduce oxidative stress and the production of free radicals and prevent cognitive decline caused by aging. In an accelerated aging rat model, vitamin $\mathrm{E}$ supplementation reduced the number of nerve cells lost due to aging (La Fata et al., 2017), and improved memory and cognitive decline due to the loss of prefrontal cortical cells (Rafati et al., 2017). Vitamin E also increased the neuronal cell area of prefrontal cortical cells, the number of glial cells and neurons, the length of synapses, and plasticity effects (Rafati et al., 2018). It also prevented changes in the shape of dendrites of nerve cells that lead to learning deficits (Veinbergs et al., 2000) and increased the density of neuroreceptors in the hippocampus of rats with neurological injury (Sayyahi et al., 2018). The concentration of vitamin $\mathrm{E}$ in the brain is negatively correlated with the concentration of $\mathrm{A} \beta$ in the brain (Morris et al., 2015) and can help reduce the accumulation of $A \beta$ in the rat brain and increase the clearance of $A \beta$ in the blood (Nishida et al., 2009). Vitamin E also prevents the metabolism of 12LOX, a key mediator of glutamate-induced neurodegeneration, by preventing arachidonic acid from entering the catalytic site of 12-LOX and enabling vitamin E to effectively prevent neuronal degeneration (Khanna et al., 2003). Furthermore, vitamin $\mathrm{E}$ can interact with vitamin $\mathrm{C}$ and flavonoids to enhance the ability of antioxidants to scavenge free radicals (Kadoma et al., 2006).

Carotenoids are widely present in plant pigments, and their chemical structure is a polymer of 8 isoprene and an oxidized derivative thereof, which is a precursor of vitamin A. Since the chemical structure of carotenoids contains many conjugated double bonds, electrons can enrich the structure while maintaining high chemical stability and fighting free radicals. At the same time, carotenoids also exhibit obvious effects for inhibiting lipid peroxidation, which can effectively prevent brain aging. According to nutrition epidemiology research, the middleaged population consuming a diet rich in carotenoids generally scores higher on neuropsychological tests than that consuming an ordinary diet (Kesse-Guyot et al., 2014). This concept is supported by the fact that carotenoids can inhibit the formation of $\mathrm{A} \beta$ in the $\mathrm{AD}$ brain (Obulesu et al., 2011) and improve the 
secretion of oxidative stress and pro-inflammatory mediators (Mohammadzadeh Honarvar et al., 2017).

In the past 10 years, natural carotenoids, such as astaxanthin (Hussein et al., 2006), crocin (Asdaq and Inamdar, 2010), and lycopene (Agarwal and Rao, 2000), have been found to exhibit neuroprotective effects. Astaxanthin is the most potent antioxidant in flavonoids and is found in the leaves and fruits of plants. When supplementing with astaxanthin in the hippocampus, neonatal mice were found to show enhanced cognitive ability compared to adult mice (Yook et al., 2016). In terms of mechanism, astaxanthin can cross the blood-brain barrier (Petri and Lundebye, 2007) to exert its antioxidant (Pan et al., 2017), anti-inflammatory (Zhang et al., 2017b), and neuroplastic effects on the brain. Astaxanthin also attenuates the increase in CHOP and ER chaperone protein via the MAPK pathway and inhibits the influx of calcium ions (Grimmig et al., 2019) and upregulates HO-1 via the ERK1/2 pathway to protect against the neurotoxicity of $\mathrm{A} \beta$ (Lin et al., 2017). It is generally known that $A \beta$ causes long-term dysfunction in the hippocampus of mice; however, the injection of crocin can improve the physiological state of cells in the hippocampus and the overall memory of mice (Lin et al., 2017). In experiments examining oxidative stress and inflammation, crocinin was shown to protect cells against neurodegeneration by activating the Akt/GSK, CREB/BDNF, and NF- $\mathrm{B}$ signaling pathways (Zhang et al., 2018; Motaghinejad et al., 2019).

Finally, lycopene is widely present in tomatoes and has high neurotrophic value (Shi and Le Maguer, 2000). In a model of $\mathrm{A} \beta$-induced neuronal injury, lycopene did not activate NF- $\mathrm{B}$, p65, or TLR4 expression (Tripathi et al., 2018), but restored mitochondrial morphological membrane potential and ATP levels (Qu et al., 2016) and inhibited Bax and mitochondria. The associated decrease in the level of Bcl-2 (Feng et al., 2016) created protective effects against inflammation and oxidative stress in nerve cells. In fact, after 14 days of eating tomatoes, the expression of dopaminergic neurons in the substantia nigra and striatum of small mammals was not reduced even under increased oxidative stress (di Matteo et al., 2009).

\section{Alkaloids}

Alkaloids are strong antioxidants with a complex structure; the more nitrogen atoms that are exposed in the heterocyclic structure, the easier it is to combine with reactive oxygen and free radicals. There are many naturally occurring plantderived alkaloids that have long been used to develop useful pharmaceutical substances (Khadem and Marles, 2011). The astragalus alkaloid and its derivatives are an important target for biological research because they are commonly found in food sources such as coffee, tea, and potatoes (Monteiro et al., 2016). The main derivatives of astragalus are methylxanthine, theophylline (1,3-dimethylxanthine), theobromine (3,7dimethylxanthine), and caffeine (1,3,7-trimethylxanthine) ( $\mathrm{Li}$ et al., 2017). Caffeine is considered to be a more beneficial derivative of astragalus to humans (Machnik et al., 2017) and can excite the central nervous system. Therefore, proper caffeine intake can be very beneficial to the nervous system in general (Cappelletti et al., 2015). Caffeine is an antagonist of adenosine
$\mathrm{A}(1)$ and $\mathrm{A}(2 \mathrm{~A})$ receptors, which are closely related to the regulation of synaptic plasticity and energy metabolism in neurons (Cellai et al., 2018). This is particularly important for neurodegenerative diseases such as epilepsy (Masino et al., 2014), in which changes in the level of adenosine can be quite prevalent. Additionally, memory loss caused by chronic stress is linked to the $\mathrm{A} 2 \mathrm{AR}$ receptor and caffeine acts as an antagonist to prevent and treat such symptoms (Kaster et al., 2015). Additionally, when considering cognitive decline caused by aging, dietary intake of caffeine can protect the brain by regulating the $\mathrm{Bax} / \mathrm{Bcl} 2$ ratio, caspase-3, and PARP-1 levels to reduce oxidative stress, and COX-2, NOS-2, TNF $\alpha$, and IL- $1 \beta$ to further reduce $\mathrm{D}$-galactose-induced neuroinflammation and neurodegeneration (Ullah et al., 2015).

Another common alkaloid that affects the nervous system is the nicotine commonly found in tobacco. A large amount of smoking and nicotine intake is an important risk factor for death. By controlling the intake of nicotine, this recognized "killer" can become a "doctor." The level of nicotine acetylcholine in the brain of smokers has been found to be much higher than in that of non-smokers and can promote the release of dopamine in the striatum (Jasinska et al., 2014). Nicotine acetylcholine receptors (nACHRs) (Hogg et al., 2003) can control the resting potential and excitatory conduction in neurons. In the $\mathrm{AD}$ brain, the $\alpha 7$ nicotinic acetylcholine receptor ( $\alpha 7 \mathrm{nAChR})$ can be damaged with $A \beta$ knots to form a complex that disrupts synaptic function (Ni et al., 2013) and using an antagonist of $\alpha 7 \mathrm{nAChR}$ can actually inhibit the proliferation of microglia and reduce the expression of inflammatory factors IL-1 $\beta$ and TNF- $\alpha$ (Guan et al., 2015). Furthermore, it has been found in humans and animals that nicotine enhances the learning ability (Poorthuis et al., 2009), improves neuronal plasticity in the hippocampus (Alkadhi, 2018), treats depression (Motaghinejad et al., 2016), and can treat excitotoxicity at low concentrations (Sieber, 2012). Through the ERK1/2 pathway (Ju et al., 2017), the PI3K-AKT pathway (Huang et al., 2012), and the mitochondrial apoptotic pathway (Akaike et al., 2010), nicotine can also protect neurons from oxidative stress-induced apoptosis.

\section{Polysaccharides}

A polysaccharide refers to the natural substance formed by polymerizing more than 10 monosaccharide molecules. Many polysaccharides have a scavenging effect on reactive oxygen species and free radicals and are responsible for many basic functions of the brain. They can bind to proteins and lipids, stabilize the structure of nerve cells and synapses (Martin, 2002), and are used as a source of cellular energy (Falkowska et al., 2015) and as a neurotransmitter precursor substance (Varki, 2017), which are essential nutrients for the brain (Nelson et al., 2012). Polysaccharides can exert many functions through the metabolism of the brain and can contribute to the formation of neurites and synapses in neurons (Miyata and Kitagawa, 2017). They can also provide energy substances such as lactic acid to neurons through the metabolism of glial cells (Falkowska et al., 2015) and in the AD brain can reduce the production of $A \beta$ to reduce toxicity (Timmer et al., 2010), inhibit certain inflammatory factors, and increase resistance to oxidative stress 
(Jia et al., 2015). Polysaccharides are also known to exert neuroprotective effects on mitochondria by reducing the ratio of Bax/Bcl-2, caspase-3 (Yu et al., 2017), P-AKT, and phosphoric acid. Similar protective effects can be observed across numerous types of nerve cells by inhibiting GSK-3 $\beta$ (Hu et al., 2016) and activating ERK (Zhang et al., 2017d) to reverse oxidative damage.

\section{Active Peptides}

A biologically active peptide, known as a polypeptide, can be obtained via the process of protein hydrolysis. The function of a polypeptide is related to its amino acid composition and structure. When ingested by humans, plant proteins are hydrolyzed by the digestive system and many small peptides and amino acids are obtained. These amino acids often activate PKA while glutamate transporters of neurons and astrocytes can promote the cascade of the MAPK reaction (Steyfkens et al., 2018). There are a wide variety of active peptides that include antioxidant peptides and opioid peptides that have important neuroprotective effects. Glutathione is an essential peptide in plant growth and development and plays an important role in the antioxidant system of animals. Specifically, glutathione peroxidase can remove large numbers of free radicals for antioxidant metabolism (Noctor et al., 2012). The mitochondrial metabolism of reactive oxygen species also requires the use of glutathione (Fernandez-Checa et al., 1998). These processes are important to counteract oxidative stress (Dukhande et al., 2013) by causing an increase in Bcl-2. Recently, it has been confirmed that in the ischemia-reperfusion model in rodents, cerebral nerve cell damage is associated with glutathione depletion, and post-ischemia recovery is associated with an increase in the concentration of glutathione (Won et al., 2015). By detecting the concentration of glutathione in the brain of $\mathrm{AD}$ patients, it was found that the concentration of glutathione was less than that of normal brains and showed an age preference (Rae and Williams, 2017). Furthermore, peptides of soy protein, rice protein, and hydrolysate of wheat gliadin derived from wheat (Teschemacher, 2003) have opioid activity and can cause an increase in the antioxidant and methylation capacity of nerve cells (Trivedi et al., 2014) and lower the NO level across the cellular environment (Yin et al., 2015). Opioid peptides act in conjunction with opioid receptors, the activation of which can inhibit P38 phosphorylation via PCK and MAPK activation, prevent cell apoptosis, and scavenge free radicals to protect nerve cells (Staples et al., 2013). In addition, scientists have recently extracted Rubisco peptides from spinach leaves that have been shown to have significant anti-anxiety effects (Kimura et al., 2018).

\section{PLANT ANTIOXIDANTS PARTICIPATE IN THE COORDINATED PROTECTION OF THE NERVOUS SYSTEM}

The nervous system is integrated with the entire human body, and plant-derived antioxidant substances are absorbed by the digestive system and then circulated throughout the body. Therefore, nerve cells in the whole body may be protected. In the nervous system, some nerve cells regulated the immune response and cell repair. Plant-derived antioxidants can protect this part of the nervous system with immune function, thereby increasing its ability to resist damage and repair itself.

\section{The Protective Effect of Glial Cells on Neurons}

Two of the most prevalent cell types in the brain are neurons and glial cells. The primary function of neurons and glial cells is to transmit information and to provide nutrients, respectively. Through co-culture experiments with glial cells and neurons, it was found that glial cells can help neurons resist oxidative stress by secreting antioxidants or helping antioxidant precursors. Glutathione has important functions in the antioxidant metabolism of the brain, but different cells in the brain have different requirements for glutathione precursors, which provide a defense against oxidation (Dringen, 2000). Plant nutrients eventually enter the bloodstream through dietary digestion, but due to the presence of the blood-brain barrier, substances in the blood are not fully absorbed and utilized by the brain. The neuro-glio-vascular unit, which is mainly composed of glial cells, is formed around the blood vessels of the brain; however, connexin $(\mathrm{Cx})$ channels allow nutrients to enter the brain and leave harmful substances in the blood vessels. The pathological state of glial cells regulates the blood-brain barrier (De Bock et al., 2017) and therefore these cells can be thought of as guardians that protect neurons against oxidative stress (Liu et al., 2018) via the Saposin C/GPR37L1/GPR37 pathway. When the brain is exposed to a certain degree of oxidative stress, glial cells can cause neuronal damage, but also secrete a large amount of neuropeptides to protect both glial cells and neurons, and improve the brain's defense against oxidative stress (Ghouili et al., 2018). Overall, glial cells can play an important role in the recovery of brain function (Toledano et al., 2016), so the protection of glial cells can be considered directly related to nervous system protection.

\section{Protective Effect of Microglia on Neurons}

Microglia are monocytes that can enter the central nervous system and generally exhibit either the M1 or M2 phenotype. Microglia with the M1 phenotype can show signs of inflammation under specific environments whereas those with the M2 phenotype generally do not. Microglia have a unique immune function in the brain (Tang and Le, 2016) by activating synaptic plasticity. Microglia also help remove brain toxins and cellular metabolic waste to maintain the homeostasis of the brain (Chen and Trapp, 2016). In a study of aging mice, neuronal degeneration was clearly seen as a function of aging (Hasegawa-Ishii et al., 2011) and the degradation and morphological changes of microglial cells increased the risk of brain damage. Nevertheless, through the timely treatment with polyphenols, the brain's ability to resist neurodegenerative diseases significantly improved (Conde and Streit, 2006; Bickford et al., 2017). Microglial cells can also be activated to clear the accumulated $\mathrm{A} \beta$ in the brain (Lee and Landreth, 2010), while resveratrol 
(Cai et al., 2017), sinomenine (Feng and Zhang, 2019), and ganoderma polysaccharide (Shukla and Sharma, 2011) can induce protection against $\mathrm{A} \beta$ damage. Recently, it was also found that plant extracts can regulate microglia to express the M2 phenotype more than the M1 phenotype (Yang et al., 2017) to reduce neuroinflammation and nerve cell damage and to clear $A \beta$ (Figure 2). Additionally, oral theaflavin can improve the cognitive behavior of LPS-induced neuroinflammation by inhibiting the activation of M1-type microglia (Ano et al., 2019). Curcumin can also protect BV2 microglia by effectively reducing the index of oxidative stress in glaucoma mice (Yue et al., 2014). Furthermore, flavonoids in plants have the ability to regulate microglial activation (inhibiting M1-type activation), which allows flavonoids to reduce various inflammatory factors in the brain (Spagnuolo et al., 2018).

\section{Protection Against the Effects of Nervous System Aging on Degenerative Diseases}

Aging is the biggest cause of $\mathrm{AD}$, mainly manifesting as the accumulation of $A \beta$ cell tangles, which eventually lead to memory (Crowther and Goedert, 2000; Selkoe and Hardy, 2016) and cognitive decline (De-Paula et al., 2012). Microglia play important roles in the immune regulation in the brain, monitoring CNS and inflammatory factors, and clearing $\mathrm{A} \beta$ and cell debris (Sarlus and Heneka, 2017). Antioxidants such as glutathione and vitamin $\mathrm{C}$ cooperate with microglia to respond to acute and chronic oxidative stress (Freitas et al., 2017). The lack of vitamin B affects the health of the entire nervous system and the gradual degradation of neurons can lead to $\mathrm{PD}, \mathrm{AD}$, or amyotrophic lateral sclerosis. Vitamin $\mathrm{B}$ deficiency can affect the health of the entire nervous system; $\mathrm{AD}$ and $\mathrm{PD}$ are caused by the gradual degeneration of nerve cells in the brain and amyotrophic lateral sclerosis (Freitas et al., 2017). The specific combination of folic acid and vitamins B, C, and E as well as others has improved the plasticity of nerve cell synaptic dysfunction (Kihara and Shimohama, 2004) and has restored the cognitive ability and memory in AD patients in various clinical trials (van Wijk et al., 2014). Furthermore, neurotrophic and antioxidant substances in plants have anti-aging effects on the nervous system and promote the functional integrity of nerve cells. On one hand, nutrients and antioxidants can promote and activate immune cells in the nervous system, which can provide antioxidant and antiinflammatory effects and nutrient supply to protect the health of the brain and the integrity of CNS function. On the other hand, antioxidant substances in plant cells can enter the brain and the whole body through the blood and can play an important

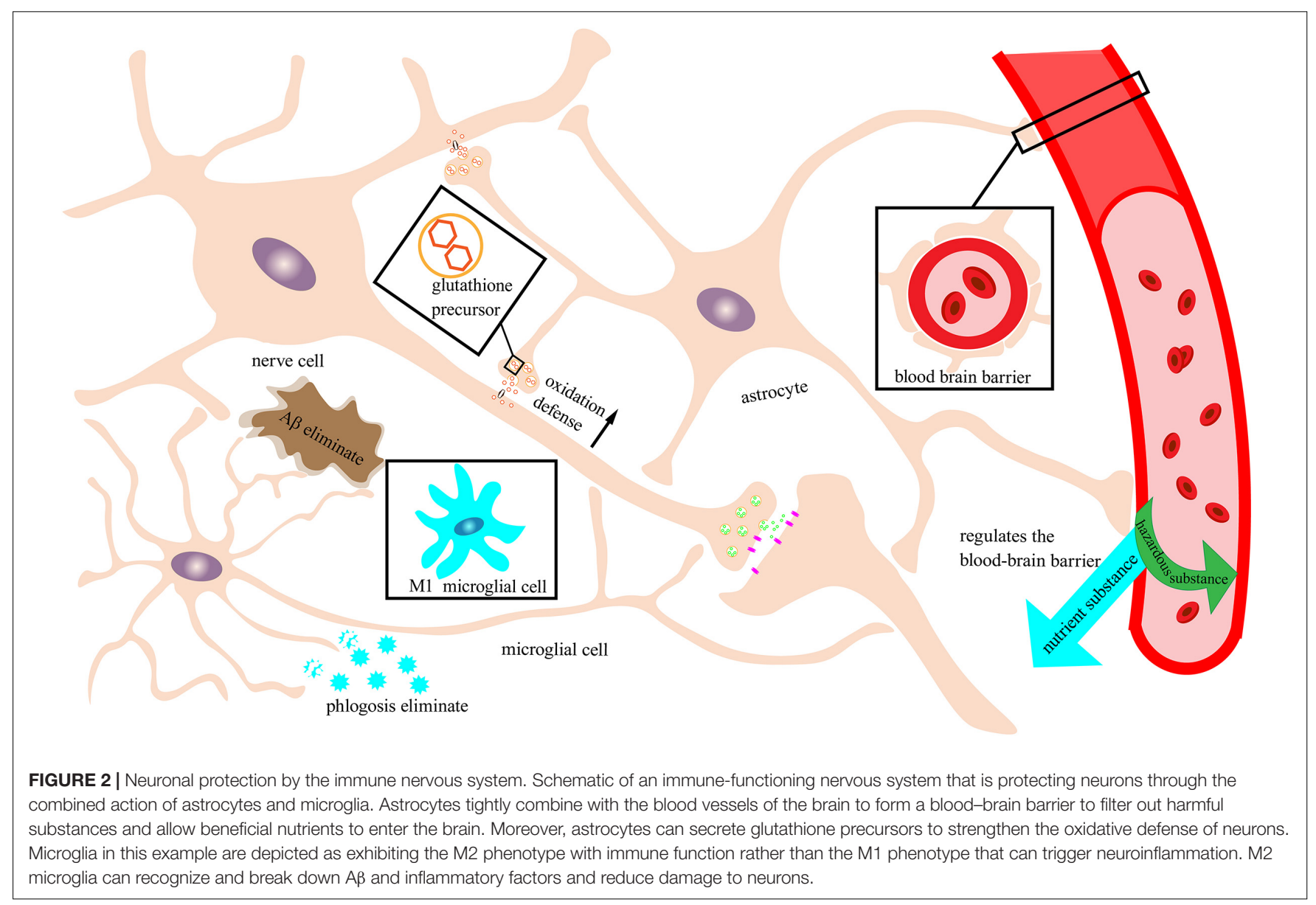


role in the enhancement of the antioxidant defense of the whole nervous system.

The functional integrity of the nervous system is inseparable from the cooperation of the nerve cells. Nerve cells each carry out their normal functions and ensure the reasonable operation of the nervous system. In terms of anti-oxidation, anti-aging, and neuroprotection, plant-derived antioxidants can eliminate free radicals in cells of various parts of the nervous system to achieve neuroprotection. The elimination of free radicals can also activate the immune regulation mechanism in the nervous system to achieve neuroprotection. In the treatment and prevention of nerve-related diseases, plant-derived antioxidants can affect both nerve cells and the nervous system as a whole. In the process of research and development of plant antioxidants, the effects of nutrients on nerve cells and the nervous system should be more widely linked so that the nutrients in plants are fully developed and utilized.

\section{REFERENCES}

Agarwal, S., and Rao, A. V. (2000). Tomato lycopene and its role in human health and chronic diseases. CMAJ 163, 739-744.

Akaike, A., Takada-Takatori, Y., Kume, T., and Izumi, Y. (2010). Mechanisms of neuroprotective effects of nicotine and acetylcholinesterase inhibitors: role of alpha4 and alpha7 receptors in neuroprotection. J. Mol. Neurosci. 40, 211-216. doi: 10.1007/s12031-009-9236-1

Alkadhi, K. A. (2018). Neuroprotective effects of nicotine on hippocampal longterm potentiation in brain disorders. J. Pharmacol. Exp. Ther. 366, 498-508. doi: 10.1124/jpet.118.247841

Ano, Y., Ohya, R., Kita, M., Taniguchi, Y., and Kondo, K. (2019). Theaflavins improve memory impairment and depression-like behavior by regulating microglial activation. Molecules 24:467. doi: 10.3390/molecules 24030467

Asdaq, S. M., and Inamdar, M. N. (2010). Potential of Crocus sativus (saffron) and its constituent, crocin, as hypolipidemic and antioxidant in rats. Appl. Biochem. Biotechnol. 162, 358-372. doi: 10.1007/s12010-009-8740-7

Assuncao, M., and Andrade, J. P. (2015). Protective action of green tea catechins in neuronal mitochondria during aging. Front. Biosci. 20, 247-262. doi: 10.2741/ 4307

Bakhtiari, M., Panahi, Y., Ameli, J., and Darvishi, B. (2017). Protective effects of flavonoids against Alzheimer's disease-related neural dysfunctions. Biomed. Pharmacother. 93, 218-229. doi: 10.1016/j.biopha.2017.06.010

Ballaz, S. J., and Rebec, G. V. (2019). Neurobiology of vitamin C: expanding the focus from antioxidant to endogenous neuromodulator. Pharmacol. Res. 146:104321. doi: 10.1016/j.phrs.2019.104321

Baluchnejadmojarad, T., Rabiee, N., Zabihnejad, S., and Roghani, M. (2017). Ellagic acid exerts protective effect in intrastriatal 6-hydroxydopamine rat model of Parkinson's disease: possible involvement of ERbeta/Nrf2/HO-1 signaling. Brain Res. 1662, 23-30. doi: 10.1016/j.brainres.2017.02.021

Berger, U. V., Lu, X. C., Liu, W., Tang, Z., Slusher, B. S., and Hediger, M. A. (2003). Effect of middle cerebral artery occlusion on mRNA expression for the sodiumcoupled vitamin C transporter SVCT2 in rat brain. J. Neurochem. 86, 896-906. doi: 10.1046/j.1471-4159.2003.01891.x

Bickford, P. C., Flowers, A., and Grimmig, B. (2017). Aging leads to altered microglial function that reduces brain resiliency increasing vulnerability to neurodegenerative diseases. Exp. Gerontol. 94, 4-8. doi: 10.1016/j.exger.2017. 01.027

Braidy, N., Jugder, B. E., Poljak, A., Jayasena, T., Nabavi, S. M., Sachdev, P., et al. (2017). Molecular targets of tannic acid in Alzheimer's disease. Curr. Alzheimer Res. 14, 861-869. doi: 10.2174/1567205014666170206163158

Cai, Q., Li, Y., and Pei, G. (2017). Polysaccharides from Ganoderma lucidum attenuate microglia-mediated neuroinflammation and modulate microglial phagocytosis and behavioural response. J. Neuroinflammation 14:63. doi: 10. 1186/s12974-017-0839-0

\section{AUTHOR CONTRIBUTIONS}

XC: writing - original draft preparation and software. QL: supervision and data curation. YL: conceptualization, writing reviewing and editing, and investigation. All authors contributed to the article and approved the submitted version.

\section{FUNDING}

This work was supported by funding from the Natural Science Foundation of Hunan Province (No. 2020JJ4138), Hunan Furong Scholars Program, Hunan Youth Excellent Talents Supporting Program (No. 2016RS3033), Scientific Research Project of Education Department of Hunan Province (No. 18A160), and Grain-oil Process and Quality Control 2011 Collaborative and Innovative Grant from Hunan Province.

Cappelletti, S., Piacentino, D., Sani, G., and Aromatario, M. (2015). Caffeine: cognitive and physical performance enhancer or psychoactive drug? Curr. Neuropharmacol. 13, 71-88. doi: 10.2174/1570159x13666141210215655

Cellai, L., Carvalho, K., Faivre, E., Deleau, A., Vieau, D., Buee, L., et al. (2018). The adenosinergic signaling: a complex but promising therapeutic target for Alzheimer's disease. Front. Neurosci. 12:520. doi: 10.3389/fnins.2018.00520

Che, F., Wang, G., Yu, J., Wang, X., Lu, Y., Fu, Q., et al. (2017). Effects of epigallocatechin3gallate on iron metabolism in spinal cord motor neurons. Mol. Med. Rep. 16, 3010-3014. doi: 10.3892/mmr.2017.6919

Chen, S. Q., Wang, Z. S., Ma, Y. X., Zhang, W., Lu, J. L., Liang, Y. R., et al. (2018). Neuroprotective effects and mechanisms of tea bioactive components in neurodegenerative diseases. Molecules 23:512. doi: 10.3390/molecules23030512

Chen, Z., and Trapp, B. D. (2016). Microglia and neuroprotection. J. Neurochem. 136(Suppl. 1), 10-17. doi: 10.1111/jnc.13062

Cheruku, S. P., Ramalingayya, G. V., Chamallamudi, M. R., Biswas, S., Nandakumar, K., Nampoothiri, M., et al. (2018). Catechin ameliorates doxorubicin-induced neuronal cytotoxicity in in vitro and episodic memory deficit in in vivo in Wistar rats. Cytotechnology 70, 245-259. doi: 10.1007/ s10616-017-0138-8

Chesser, A. S., Ganeshan, V., Yang, J., and Johnson, G. V. (2016). Epigallocatechin3-gallate enhances clearance of phosphorylated tau in primary neurons. Nutr. Neurosci. 19, 21-31. doi: 10.1179/1476830515y.0000000038

Conde, J. R., and Streit, W. J. (2006). Microglia in the aging brain. J. Neuropathol. Exp. Neurol. 65, 199-203. doi: 10.1097/01.jnen.0000202887.22082.63

Crowther, R. A., and Goedert, M. (2000). Abnormal tau-containing filaments in neurodegenerative diseases. J. Struct. Biol. 130, 271-279. doi: 10.1006/jsbi.2000. 4270

Datla, K. P., Zbarsky, V., Rai, D., Parkar, S., Osakabe, N., Aruoma, O. I., et al. (2007). Short-term supplementation with plant extracts rich in flavonoids protect nigrostriatal dopaminergic neurons in a rat model of Parkinson's disease. J. Am. Coll. Nutr. 26, 341-349. doi: 10.1080/07315724.2007.10719621

De Bock, M., Leybaert, L., and Giaume, C. (2017). Connexin channels at the gliovascular interface: gatekeepers of the brain. Neurochem. Res. 42, 2519-2536. doi: $10.1007 / \mathrm{s} 11064-017-2313-\mathrm{x}$

Del Rio, L. A. (2015). ROS and RNS in plant physiology: an overview. J. Exp. Bot. 66, 2827-2837. doi: 10.1093/jxb/erv099

De-Paula, V. J., Radanovic, M., Diniz, B. S., and Forlenza, O. V. (2012). Alzheimer's disease. Subcell Biochem. 65, 329-352. doi: 10.1007/978-94-007-5416-4_14

di Matteo, V., Pierucci, M., Di Giovanni, G., Dragani, L. K., Murzilli, S., Poggi, A., et al. (2009). Intake of tomato-enriched diet protects from 6-hydroxydopamineinduced degeneration of rat nigral dopaminergic neurons. J. Neural Trans. Suppl. 73, 333-341. doi: 10.1007/978-3-211-92660-4_28

Dos Santos Souza, C., Grangeiro, M. S., Lima Pereira, E. P., Dos Santos, C. C., da Silva, A. B., Sampaio, G. P., et al. (2018). Agathisflavone, a flavonoid derived from Poincianella pyramidalis (Tul.), enhances neuronal population 
and protects against glutamate excitotoxicity. Neurotoxicology 65, 85-97. doi: 10.1016/j.neuro.2018.02.001

Dringen, R. (2000). Metabolism and functions of glutathione in brain. Prog. Neurobiol. 62, 649-671. doi: 10.1016/s0301-0082(99)00060-x

Dukhande, V. V., Kawikova, I., Bothwell, A. L., and Lai, J. C. (2013). Neuroprotection against neuroblastoma cell death induced by depletion of mitochondrial glutathione. Apoptosis 18, 702-712. doi: 10.1007/s10495-0130836- 4

Duthie, G., and Crozier, A. (2000). Plant-derived phenolic antioxidants. Curr. Opin. Clin. Nutr. Metab. Care 3, 447-451. doi: 10.1097/00075197-20001100000006

Ebrahimzadeh-Bideskan, A. R., Hami, J., Alipour, F., Haghir, H., Fazel, A. R., and Sadeghi, A. (2016). Protective effects of ascorbic acid and garlic extract against lead-induced apoptosis in developing rat hippocampus. Metab. Brain Dis. 31, 1123-1132. doi: 10.1007/s11011-016-9837-7

El-Sayed el, S. M., Abo-Salem, O. M., Abd-Ellah, M. F., and Abd-Alla, G. M. (2008). Hesperidin, an antioxidant flavonoid, prevents acrylonitrile-induced oxidative stress in rat brain. J. Biochem. Mol. Toxicol. 22, 268-273. doi: 10.1002/jbt.20237

Falkowska, A., Gutowska, I., Goschorska, M., Nowacki, P., Chlubek, D., and Baranowska-Bosiacka, I. (2015). Energy metabolism of the brain, including the cooperation between astrocytes and neurons, especially in the context of glycogen metabolism. Int. J. Mol. Sci. 16, 25959-25981. doi: 10.3390/ ijms161125939

Feng, C., Luo, T., Zhang, S., Liu, K., Zhang, Y., Luo, Y., et al. (2016). Lycopene protects human SHSY5Y neuroblastoma cells against hydrogen peroxideinduced death via inhibition of oxidative stress and mitochondriaassociated apoptotic pathways. Mol. Med. Rep. 13, 4205-4214. doi: $10.3892 / \mathrm{mmr} .2016 .5056$

Feng, L., and Zhang, L. (2019). Resveratrol suppresses abeta-induced microglial activation through the TXNIP/TRX/NLRP3 signaling pathway. DNA Cell Biol. 38, 874-879. doi: 10.1089/dna.2018.4308

Fernandez-Checa, J. C., Garcia-Ruiz, C., Colell, A., Morales, A., Mari, M., Miranda, M., et al. (1998). Oxidative stress: role of mitochondria and protection by glutathione. Biofactors 8, 7-11. doi: 10.1002/biof.5520080102

Firdaus, F., Zafeer, M. F., Anis, E., Ahmad, M., and Afzal, M. (2018). Ellagic acid attenuates arsenic induced neuro-inflammation and mitochondrial dysfunction associated apoptosis. Toxicol. Rep. 5, 411-417. doi: 10.1016/j.toxrep.2018. 02.017

Freitas, H. R., Ferreira, G. D. C., Trevenzoli, I. H., Oliveira, K. J., and de Melo Reis, R. A. (2017). Fatty acids, antioxidants and physical activity in brain aging. Nutrients 9:1263. doi: 10.3390/nu9111263

Ganie, S. A., Dar, T. A., Zargar, B., Hamid, R., Zargar, O., Dar, P. A., et al. (2014). Antioxidant and hepatoprotective effects of Crataegus songarica methanol extract. J. Environ. Pathol. Toxicol. Oncol. 33, 131-143. doi: 10.1615/ jenvironpatholtoxicoloncol.2014010606

Gao, L. P., Wei, H. L., Zhao, H. S., Xiao, S. Y., and Zheng, R. L. (2005). Antiapoptotic and antioxidant effects of rosmarinic acid in astrocytes. Pharmazie 60, 62-65.

Ghaffari, H., Venkataramana, M., Jalali Ghassam, B., Chandra Nayaka, S., Nataraju, A., Geetha, N. P., et al. (2014). Rosmarinic acid mediated neuroprotective effects against $\mathrm{H}_{2} \mathrm{O}_{2}$-induced neuronal cell damage in N2A cells. Life Sci. 113, 7-13. doi: 10.1016/j.lfs.2014.07.010

Ghouili, I., Bahdoudi, S., Morin, F., Amri, F., Hamdi, Y., Coly, P. M., et al. (2018). Endogenous expression of ODN-related peptides in astrocytes contributes to cell protection against oxidative stress: astrocyte-neuron crosstalk relevance for neuronal survival. Mol. Neurobiol. 55, 4596-4611. doi: 10.1007/s12035-0170630-3

Goedert, M. (2015). NEURODEGENERATION. Alzheimer's and Parkinson's diseases: the prion concept in relation to assembled Abeta, tau, and alphasynuclein. Science 349:1255555. doi: 10.1126/science.1255555

Graf, E. (1992). Antioxidant potential of ferulic acid. Free Radic. Biol. Med. 13, 435-448. doi: 10.1016/0891-5849(92)90184-i

Grimmig, B., Hudson, C., Moss, L., Peters, M., Subbarayan, M., Weeber, E. J., et al. (2019). Astaxanthin supplementation modulates cognitive function and synaptic plasticity in young and aged mice. Geroscience 41, 77-87. doi: 10.1007/ s11357-019-00051-9

Guan, Y. Z., Jin, X. D., Guan, L. X., Yan, H. C., Wang, P., Gong, Z., et al. (2015). Nicotine inhibits microglial proliferation and is neuroprotective in global ischemia rats. Mol. Neurobiol. 51, 1480-1488. doi: 10.1007/s12035-014-8825-3
Guo, Y. E., Suo, N., Cui, X., Yuan, Q., and Xie, X. (2018). Vitamin C promotes oligodendrocytes generation and remyelination. Glia 66, 1302-1316. doi: 10 . 1002/glia.23306

Hasegawa-Ishii, S., Takei, S., Chiba, Y., Furukawa, A., Umegaki, H., Iguchi, A., et al. (2011). Morphological impairments in microglia precede age-related neuronal degeneration in senescence-accelerated mice. Neuropathology 31, 20-28. doi: 10.1111/j.1440-1789.2010.01126.x

Hassan, W., Noreen, H., Rehman, S., Gul, S., Kamal, M. A., Kamdem, J. P., et al. (2017). Oxidative stress and antioxidant potential of one hundred medicinal plants. Curr. Top. Med. Chem. 17, 1336-1370. doi: 10.2174/ 1568026617666170102125648

Hassanzadeh, P., Arbabi, E., Atyabi, F., and Dinarvand, R. (2017). Ferulic acid exhibits antiepileptogenic effect and prevents oxidative stress and cognitive impairment in the kindling model of epilepsy. Life Sci. 179, 9-14. doi: 10.1016/ j.lfs.2016.08.011

Hogg, R. C., Raggenbass, M., and Bertrand, D. (2003). Nicotinic acetylcholine receptors: from structure to brain function. Rev. Physiol. Biochem. Pharmacol. 147, 1-46. doi: 10.1007/s10254-003-0005-1

Hu, S., Wang, D., Zhang, J., Du, M., Cheng, Y., Liu, Y., et al. (2016). Mitochondria related pathway is essential for polysaccharides purified from Sparassis crispa mediated neuro-protection against glutamate-induced toxicity in differentiated PC12 cells. Int. J. Mol. Sci. 17:133. doi: 10.3390/ijms17020133

Huang, X., Cheng, Z., Su, Q., Zhu, X., Wang, Q., Chen, R., et al. (2012). Neuroprotection by nicotine against colchicine-induced apoptosis is mediated by PI3-kinase-Akt pathways. Int. J. Neurosci. 122, 324-332. doi: 10.3109/ 00207454.2012.657377

Hussein, G., Sankawa, U., Goto, H., Matsumoto, K., and Watanabe, H. (2006). Astaxanthin, a carotenoid with potential in human health and nutrition. J. Nat. Prod. 69, 443-449. doi: 10.1021/np050354\%2B

Jaeger, B. N., Parylak, S. L., and Gage, F. H. (2018). Mechanisms of dietary flavonoid action in neuronal function and neuroinflammation. Mol. Aspects Med. 61, 50-62. doi: 10.1016/j.mam.2017.11.003

Jasinska, A. J., Zorick, T., Brody, A. L., and Stein, E. A. (2014). Dual role of nicotine in addiction and cognition: a review of neuroimaging studies in humans. Neuropharmacology 84, 111-122. doi: 10.1016/j.neuropharm.2013.02.015

Jeong, J. Y., Cha, H. J., Choi, E. O., Kim, C. H., Kim, G. Y., Yoo, Y. H., et al. (2019). Activation of the Nrf2/HO-1 signaling pathway contributes to the protective effects of baicalein against oxidative stress-induced DNA damage and apoptosis in HEI193 Schwann cells. Int. J. Med. Sci. 16, 145-155. doi: 10.7150/ijms.27005

Jia, D., Rao, C., Xue, S., and Lei, J. (2015). Purification, characterization and neuroprotective effects of a polysaccharide from Gynostemma pentaphyllum. Carbohydr. Polym. 122, 93-100. doi: 10.1016/j.carbpol.2014.12.032

Jiang, T., Sun, Q., and Chen, S. (2016). Oxidative stress: a major pathogenesis and potential therapeutic target of antioxidative agents in Parkinson's disease and Alzheimer's disease. Prog. Neurobiol. 147, 1-19. doi: 10.1016/j.pneurobio.2016. 07.005

Ju, Y., Asahi, T., and Sawamura, N. (2017). Arctic Abeta40 blocks the nicotineinduced neuroprotective effect of CHRNA7 by inhibiting the ERK1/2 pathway in human neuroblastoma cells. Neurochem. Int. 110, 49-56. doi: 10.1016/j. neuint.2017.09.005

Jung, U. J., and Kim, S. R. (2018). Beneficial effects of flavonoids against Parkinson's disease. J. Med. Food 21, 421-432. doi: 10.1089/jmf.2017.4078

Kadoma, Y., Ishihara, M., Okada, N., and Fujisawa, S. (2006). Free radical interaction between vitamin $\mathrm{E}$ ( alpha-, beta-, gamma- and delta-tocopherol), ascorbate and flavonoids. In Vivo 20, 823-827.

Kantar Gok, D., Hidisoglu, E., Ocak, G. A., Er, H., Acun, A. D., and Yargicoglu, P. (2018). Protective role of rosmarinic acid on amyloid beta 42-induced echoic memory decline: implication of oxidative stress and cholinergic impairment. Neurochem. Int. 118, 1-13. doi: 10.1016/j.neuint.2018.04.008

Kaster, M. P., Machado, N. J., Silva, H. B., Nunes, A., Ardais, A. P., Santana, M., et al. (2015). Caffeine acts through neuronal adenosine A2A receptors to prevent mood and memory dysfunction triggered by chronic stress. Proc. Natl. Acad. Sci. U.S.A. 112, 7833-7838. doi: 10.1073/pnas. 1423088112

Kesse-Guyot, E., Andreeva, V. A., Ducros, V., Jeandel, C., Julia, C., Hercberg, S., et al. (2014). Carotenoid-rich dietary patterns during midlife and subsequent cognitive function. Br. J. Nutr. 111, 915-923. doi: 10.1017/s0007114513003188

Khadem, S., and Marles, R. J. (2011). Chromone and flavonoid alkaloids: occurrence and bioactivity. Molecules 17, 191-206. doi: 10.3390/molecules 17010191 
Khalil, S. R., and Hussein, M. M. (2015). Neurotransmitters and neuronal apoptotic cell death of chronically aluminum intoxicated Nile catfish (Clarias gariepinus) in response to ascorbic acid supplementation. Neurotoxicology 51, 184-191. doi: 10.1016/j.neuro.2015.09.008

Khanna, S., Roy, S., Ryu, H., Bahadduri, P., Swaan, P. W., Ratan, R. R., et al. (2003). Molecular basis of vitamin E action: tocotrienol modulates 12-lipoxygenase, a key mediator of glutamate-induced neurodegeneration. J. Biol. Chem. 278, 43508-43515. doi: 10.1074/jbc.M307075200

Kihara, T., and Shimohama, S. (2004). Alzheimer's disease and acetylcholine receptors. Acta Neurobiol. Exp. 64, 99-105.

Kimura, S., Uchida, T., Tokuyama, Y., Hosokawa, M., Nakato, J., Kurabayashi, A., et al. (2018). Identification of Rubisco anxiolytic-like peptides (rALPs) by comprehensive analysis of spinach green leaf protein digest. Biochem. Biophys. Res. Commun. 505, 1050-1056. doi: 10.1016/j.bbrc.2018.09.195

La Fata, G., van Vliet, N., Barnhoorn, S., Brandt, R. M. C., Etheve, S., Chenal, E., et al. (2017). Vitamin E supplementation reduces cellular loss in the brain of a premature aging mouse model. J. Prev. Alzheimers Dis. 4, 226-235. doi: 10.14283/jpad.2017.30

Lee, C. Y., and Landreth, G. E. (2010). The role of microglia in amyloid clearance from the AD brain. J. Neural Transm. 117, 949-960. doi: 10.1007/s00702-0100433-4

Lee, H. J., Cho, H. S., Park, E., Kim, S., Lee, S. Y., Kim, C. S., et al. (2008). Rosmarinic acid protects human dopaminergic neuronal cells against hydrogen peroxide-induced apoptosis. Toxicology 250, 109-115. doi: 10.1016/j.tox.2008. 06.010

Lenzi, J., Rodrigues, A. F., de Sousa Ros, A., de Castro, A. B., de Lima, D. D., Magro, D. D., et al. (2015). Erratum to: Ferulic acid chronic treatment exerts antidepressant-like effect: role of antioxidant defense system. Metab. Brain Dis. 30:1465. doi: 10.1007/s11011-015-9751-4

Li, G., Wang, X., and Row, K. H. (2017). Magnetic solid-phase extraction with $\mathrm{Fe}(3) \mathrm{O}(4) /$ molecularly imprinted polymers modified by deep eutectic solvents and ionic liquids for the rapid purification of alkaloid isomers (Theobromine and Theophylline) from Green Tea. Molecules 22:1061. doi: 10.3390/molecules22071061

Li, L., Li, Y., Fan, Z., Wang, X., Li, Z., Wen, J., et al. (2019). Ascorbic acid facilitates neural regeneration after sciatic nerve crush injury. Front. Cell. Neurosci. 13:108. doi: 10.3389/fncel.2019.00108

Lin, W. C., Peng, Y. F., and Hou, C. W. (2015). Ferulic acid protects PC12 neurons against hypoxia by inhibiting the p-MAPKs and COX-2 pathways. Iran. J. Basic Med. Sci. 18, 478-484.

Lin, X., Zhao, Y., and Li, S. (2017). Astaxanthin attenuates glutamate-induced apoptosis via inhibition of calcium influx and endoplasmic reticulum stress. Eur. J. Pharmacol. 806, 43-51. doi: 10.1016/j.ejphar.2017.04.008

Liochev, S. I. (2013). Reactive oxygen species and the free radical theory of aging. Free Radic. Biol. Med. 60, 1-4. doi: 10.1016/j.freeradbiomed.2013. 02.011

Liu, B., Mosienko, V., Vaccari Cardoso, B., Prokudina, D., Huentelman, M., Teschemacher, A. G., et al. (2018). Glio- and neuro-protection by prosaposin is mediated by orphan G-protein coupled receptors GPR37L1 and GPR37. Glia 66, 2414-2426. doi: 10.1002/glia.23480

Liu, Q. S., Deng, R., Li, S., Li, X., Li, K., Kebaituli, G., et al. (2017). Ellagic acid protects against neuron damage in ischemic stroke through regulating the ratio of Bcl-2/Bax expression. Appl. Physiol. Nutr. Metab. 42, 855-860. doi: 10.1139/ apnm-2016-0651

Lutz, J. A., Carter, M., Fields, L., Barron, S., and Littleton, J. M. (2015). The dietary flavonoid rhamnetin inhibits both inflammation and excitotoxicity during ethanol withdrawal in rat organotypic hippocampal slice cultures. Alcohol. Clin. Exp. Res. 39, 2345-2353. doi: 10.1111/acer.12896

Machnik, M., Kaiser, S., Koppe, S., Kietzmann, M., Schenk, I., Due, M., et al. (2017). Control of methylxanthines in the competition horse: pharmacokinetic/pharmacodynamic studies on caffeine, theobromine and theophylline for the assessment of irrelevant concentrations. Drug Test Anal. 9, 1372-1384. doi: 10.1002/dta.2097

Martin, P. T. (2002). Glycobiology of the synapse. Glycobiology 12, 1r-7r. doi: 10.1093/glycob/12.1.1r

Masino, S. A., Kawamura, M. Jr., and Ruskin, D. N. (2014). Adenosine receptors and epilepsy: current evidence and future potential. Int. Rev. Neurobiol. 119, 233-255. doi: 10.1016/b978-0-12-801022-8.00011-8
Matias, I., Diniz, L. P., Buosi, A., Neves, G., Stipursky, J., and Gomes, F. C. A. (2017). Flavonoid hesperidin induces synapse formation and improves memory performance through the astrocytic TGF-beta1. Front. Aging Neurosci. 9:184. doi: 10.3389/fnagi.2017.00184

Miyata, S., and Kitagawa, H. (2017). Formation and remodeling of the brain extracellular matrix in neural plasticity: roles of chondroitin sulfate and hyaluronan. Biochim. Biophys. Acta 1861, 2420-2434. doi: 10.1016/j.bbagen. 2017.06.010

Mohammadzadeh Honarvar, N., Saedisomeolia, A., Abdolahi, M., Shayeganrad, A., Taheri Sangsari, G., Hassanzadeh Rad, B., et al. (2017). Molecular antiinflammatory mechanisms of retinoids and carotenoids in Alzheimer's disease: a review of current evidence. J. Mol. Neurosci. 61, 289-304. doi: 10.1007/s12031016-0857-x

Monteiro, J. P., Alves, M. G., Oliveira, P. F., and Silva, B. M. (2016). Structure-bioactivity relationships of methylxanthines: trying to make sense of all the promises and the drawbacks. Molecules 21:974. doi: 10.3390/ molecules 21080974

Morris, M. C., Schneider, J. A., Li, H., Tangney, C. C., Nag, S., Bennett, D. A., et al. (2015). Brain tocopherols related to Alzheimer's disease neuropathology in humans. Alzheimers Dement. 11, 32-39. doi: 10.1016/j.jalz.2013.12.015

Motaghinejad, M., Fatima, S., Karimian, M., and Ganji, S. (2016). Protective effects of forced exercise against nicotine-induced anxiety, depression and cognition impairment in rat. J. Basic Clin. Physiol. Pharmacol. 27, 19-27. doi: 10.1515/ jbcpp-2014-0128

Motaghinejad, M., Safari, S., Feizipour, S., and Sadr, S. (2019). Crocin may be useful to prevent or treatment of alcohol induced neurodegeneration and neurobehavioral sequels via modulation of CREB/BDNF and Akt/GSK signaling pathway. Med. Hypotheses 124, 21-25. doi: 10.1016/j.mehy.2019. 01.017

Nagarajan, S., Chellappan, D. R., Chinnaswamy, P., and Thulasingam, S. (2015). Ferulic acid pretreatment mitigates MPTP-induced motor impairment and histopathological alterations in C57BL/6 mice. Pharm. Biol. 53, 1591-1601. doi: 10.3109/13880209.2014.993041

Nelson, E. D., Ramberg, J. E., Best, T., and Sinnott, R. A. (2012). Neurologic effects of exogenous saccharides: a review of controlled human, animal, and in vitro studies. Nutr. Neurosci. 15, 149-162. doi: 10.1179/1476830512y.0000000004

Ni, R., Marutle, A., and Nordberg, A. (2013). Modulation of alpha7 nicotinic acetylcholine receptor and fibrillar amyloid-beta interactions in Alzheimer's disease brain. J. Alzheimers Dis. 33, 841-851. doi: 10.3233/jad-2012-121447

Nishida, Y., Ito, S., Ohtsuki, S., Yamamoto, N., Takahashi, T., Iwata, N., et al. (2009). Depletion of vitamin E increases amyloid beta accumulation by decreasing its clearances from brain and blood in a mouse model of Alzheimer disease. J. Biol. Chem. 284, 33400-33408. doi: 10.1074/jbc.M109.054056

No author (2015). Correction: curcumin, and Apigenin - novel, and promising therapeutics against chronic neuroinflammation in Alzheimer's disease. Neural Regen. Res. 10:2017. doi: 10.4103/1673-5374.172334

Noctor, G., Mhamdi, A., Chaouch, S., Han, Y., Neukermans, J., Marquez-Garcia, B., et al. (2012). Glutathione in plants: an integrated overview. Plant Cell Environ. 35, 454-484. doi: 10.1111/j.1365-3040.2011.02400.x

Obulesu, M., Dowlathabad, M. R., and Bramhachari, P. V. (2011). Carotenoids and Alzheimer's disease: an insight into therapeutic role of retinoids in animal models. Neurochem. Int. 59, 535-541. doi: 10.1016/j.neuint.2011.04.004

Omar, S. H., Scott, C. J., Hamlin, A. S., and Obied, H. K. (2017). The protective role of plant biophenols in mechanisms of Alzheimer's disease. J. Nutr. Biochem. 47, 1-20. doi: 10.1016/j.jnutbio.2017.02.016

Pan, L., Zhou, Y., Li, X. F., Wan, Q. J., and Yu, L. H. (2017). Preventive treatment of astaxanthin provides neuroprotection through suppression of reactive oxygen species and activation of antioxidant defense pathway after stroke in rats. Brain Res. Bull. 130, 211-220. doi: 10.1016/j.brainresbull.2017.01.024

Petri, D., and Lundebye, A. K. (2007). Tissue distribution of astaxanthin in rats following exposure to graded levels in the feed. Comp. Biochem. Physiol. C Toxicol. Pharmacol. 145, 202-209. doi: 10.1016/j.cbpc.2006.12.008

Pietta, P. G. (2000). Flavonoids as antioxidants. J. Nat. Prod. 63, 1035-1042. doi: $10.1021 / \mathrm{np} 9904509$

Poorthuis, R. B., Goriounova, N. A., Couey, J. J., and Mansvelder, H. D. (2009). Nicotinic actions on neuronal networks for cognition: general principles and long-term consequences. Biochem. Pharmacol. 78, 668-676. doi: 10.1016/j.bcp. 2009.04.031 
Qu, M., Jiang, Z., Liao, Y., Song, Z., and Nan, X. (2016). Lycopene prevents amyloid [beta]-induced mitochondrial oxidative stress and dysfunctions in cultured rat cortical neurons. Neurochem. Res. 41, 1354-1364. doi: 10.1007/s11064-0161837-9

Rae, C. D., and Williams, S. R. (2017). Glutathione in the human brain: review of its roles and measurement by magnetic resonance spectroscopy. Anal. Biochem. 529, 127-143. doi: 10.1016/j.ab.2016.12.022

Rafati, A., Noorafshan, A., Jahangir, M., Hosseini, L., and Karbalay-Doust, S. (2018). Vitamin E can improve behavioral tests impairment, cell loss, and dendrite changes in rats' medial prefrontal cortex induced by acceptable daily dose of aspartame. Acta Histochem. 120, 46-55. doi: 10.1016/j.acthis.2017. 11.004

Rafati, A., Nourzei, N., Karbalay-Doust, S., and Noorafshan, A. (2017). Using vitamin $\mathrm{E}$ to prevent the impairment in behavioral test, cell loss and dendrite changes in medial prefrontal cortex induced by tartrazine in rats. Acta Histochem. 119, 172-180. doi: 10.1016/j.acthis.2017.01.004

Rehman, S. U., Ali, T., Alam, S. I., Ullah, R., Zeb, A., Lee, K. W., et al. (2019). Ferulic Acid Rescues LPS-induced neurotoxicity via modulation of the TLR4 receptor in the mouse hippocampus. Mol. Neurobiol. 56, 2774-2790. doi: 10. 1007/s12035-018-1280-9

Rohr, D., Halfter, H., Schulz, J. B., Young, P., and Gess, B. (2017). Sodiumdependent Vitamin $\mathrm{C}$ transporter 2 deficiency impairs myelination and remyelination after injury: Roles of collagen and demethylation. Glia 65, 11861200. doi: 10.1002/glia.23152

Sarkaki, A., Farbood, Y., Dolatshahi, M., Mansouri, S. M., and Khodadadi, A. (2016). Neuroprotective effects of Ellagic acid in a rat model of Parkinson's disease. Acta Med. Iran. 54, 494-502.

Sarkozi, K., Papp, A., Horvath, E., Mate, Z., Ferencz, A., Hermesz, E., et al. (2016). Green tea and vitamin $\mathrm{C}$ ameliorate some neuro-functional and biochemical signs of arsenic toxicity in rats. Nutr. Neurosci. 19, 102-109. doi: 10.1179/ 1476830514y.0000000151

Sarlus, H., and Heneka, M. T. (2017). Microglia in Alzheimer's disease. J. Clin. Invest. 127, 3240-3249. doi: 10.1172/jci90606

Sayyahi, A., Jahanshahi, M., Amini, H., and Sepehri, H. (2018). Vitamin E can compensate the density of M1 receptors in the hippocampus of scopolaminetreated rats. Folia Neuropathol. 56, 215-228. doi: 10.5114/fn.2018.78703

Selkoe, D. J., and Hardy, J. (2016). The amyloid hypothesis of Alzheimer's disease at 25 years. EMBO Mol. Med. 8, 595-608. doi: 10.15252/emmm.201606210

Shi, J., and Le Maguer, M. (2000). Lycopene in tomatoes: chemical and physical properties affected by food processing. Crit. Rev. Biotechnol. 20, 293-334. doi: 10.1080/07388550091144212

Shukla, S. M., and Sharma, S. K. (2011). Sinomenine inhibits microglial activation by Abeta and confers neuroprotection. J. Neuroinflammation 8:117. doi: 10 . 1186/1742-2094-8-117

Sieber, M. (2012). Neuroprotective properties of nicotine. Curr. Med. Chem. 19, 292-297. doi: 10.2174/092986712803414222

Song, J. H., Lee, H. J., and Kang, K. S. (2019). Procyanidin C1 Activates the Nrf2/HO-1 signaling pathway to prevent glutamate-induced apoptotic HT22 cell death. Int. J. Mol. Sci. 20:142. doi: 10.3390/ijms20010142

Spagnuolo, C., Moccia, S., and Russo, G. L. (2018). Anti-inflammatory effects of flavonoids in neurodegenerative disorders. Eur. J. Med. Chem. 153, 105-115. doi: 10.1016/j.ejmech.2017.09.001

Staples, M., Acosta, S., Tajiri, N., Pabon, M., Kaneko, Y., and Borlongan, C. V. (2013). Delta opioid receptor and its peptide: a receptor-ligand neuroprotection. Int. J. Mol. Sci. 14, 17410-17419. doi: 10.3390/ijms14091 7410

Steyfkens, F., Zhang, Z., Van Zeebroeck, G., and Thevelein, J. M. (2018). Multiple transceptors for macro- and micro-nutrients control diverse cellular properties through the PKA pathway in yeast: a paradigm for the rapidly expanding world of eukaryotic nutrient transceptors up to those in human cells. Front. Pharmacol. 9:191. doi: 10.3389/fphar.2018.00191

Tang, Y., and Le, W. (2016). Differential roles of M1 and M2 microglia in neurodegenerative diseases. Mol. Neurobiol. 53, 1181-1194. doi: 10.1007/ s12035-014-9070-5

Teschemacher, H. (2003). Opioid receptor ligands derived from food proteins. Curr. Pharm. Des. 9, 1331-1344. doi: 10.2174/1381612033454856

Timmer, N. M., van Dijk, L., van der Zee, C. E., Kiliaan, A., de Waal, R. M., and Verbeek, M. M. (2010). Enoxaparin treatment administered at both early and late stages of amyloid beta deposition improves cognition of APPswe/PS1dE9 mice with differential effects on brain Abeta levels. Neurobiol. Dis. 40, 340-347. doi: 10.1016/j.nbd.2010.06.008

Toledano, A., Alvarez, M. I., Toledano-Diaz, A., Merino, J. J., and Rodriguez, J. J. (2016). Brain local and regional neuroglial alterations in Alzheimer's Disease: cell types, responses and implications. Curr. Alzheimer Res. 13, 321-342. doi: $10.2174 / 1567205013666151116141217$

Tripathi, R., Liu, Z., and Plattner, R. (2018). EnABLing Tumor Growth and Progression: recent progress in unraveling the functions of ABL kinases in solid tumor cells. Curr. Pharmacol. Rep. 4, 367-379. doi: 10.1007/s40495-018-0149-y

Trivedi, M. S., Shah, J. S., Al-Mughairy, S., Hodgson, N. W., Simms, B., Trooskens, G. A., et al. (2014). Food-derived opioid peptides inhibit cysteine uptake with redox and epigenetic consequences. J. Nutr. Biochem. 25, 1011-1018. doi: 10. 1016/j.jnutbio.2014.05.004

Ullah, F., Ali, T., Ullah, N., and Kim, M. O. (2015). Caffeine prevents d-galactose-induced cognitive deficits, oxidative stress, neuroinflammation and neurodegeneration in the adult rat brain. Neurochem. Int. 90, 114-124. doi: 10.1016/j.neuint.2015.07.001

van Wijk, N., Broersen, L. M., de Wilde, M. C., Hageman, R. J., Groenendijk M., Sijben, J. W., et al. (2014). Targeting synaptic dysfunction in Alzheimer's disease by administering a specific nutrient combination. J. Alzheimers Dis. 38, 459-479. doi: 10.3233/jad-130998

Varki, A. (2017). Biological roles of glycans. Glycobiology 27, 3-49. doi: 10.1093/ glycob/cww086

Veinbergs, I., Mallory, M., Sagara, Y., and Masliah, E. (2000). Vitamin E supplementation prevents spatial learning deficits and dendritic alterations in aged apolipoprotein E-deficient mice. Eur. J. Neurosci. 12, 4541-4546. doi: 10.1046/j.1460-9568.2000.01308.x

Visentin, C., Pellistri, F., Natalello, A., Vertemara, J., Bonanomi, M., Gatta, E., et al. (2017). Epigallocatechin-3-gallate and related phenol compounds redirect the amyloidogenic aggregation pathway of ataxin-3 towards non-toxic aggregates and prevent toxicity in neural cells and Caenorhabditis elegans animal model. Hum. Mol. Genet. 26, 3271-3284. doi: 10.1093/hmg/ddx211

Wang, G. Q., He, X. M., Zhu, G. F., Li, D. D., Shi, J. S., and Zhang, F. (2019). Ellagic acid supports neuron by regulating astroglia Nrf2. Biotechnol. Appl. Biochem. 66, 738-743. doi: 10.1002/bab.1791

Wojtunik-Kulesza, K. A., Oniszczuk, A., Oniszczuk, T., and WaksmundzkaHajnos, M. (2016). The influence of common free radicals and antioxidants on development of Alzheimer's Disease. Biomed. Pharmacother. 78, 39-49. doi: 10.1016/j.biopha.2015.12.024

Won, S. J., Kim, J. E., Cittolin-Santos, G. F., and Swanson, R. A. (2015). Assessment at the single-cell level identifies neuronal glutathione depletion as both a cause and effect of ischemia-reperfusion oxidative stress. J. Neurosci. 35, 7143-7152. doi: 10.1523/jneurosci.4826-14.2015

Yang, X., Xu, S., Qian, Y., and Xiao, Q. (2017). Resveratrol regulates microglia M1/M2 polarization via PGC-1alpha in conditions of neuroinflammatory injury. Brain Behav. Immun. 64, 162-172. doi: 10.1016/j.bbi.2017.03.003

Yin, H., Cai, H. Z., Wang, S. K., Yang, L. G., and Sun, G. J. (2015). Wheat peptides reduce oxidative stress and inhibit NO production through modulating muopioid receptor in a rat NSAID-induced stomach damage model. Chin. J. Nat. Med. 13, 22-29. doi: 10.1016/s1875-5364(15)60003-6

Yook, J. S., Okamoto, M., Rakwal, R., Shibato, J., Lee, M. C., Matsui, T., et al. (2016). Astaxanthin supplementation enhances adult hippocampal neurogenesis and spatial memory in mice. Mol. Nutr. Food Res. 60, 589-599. doi: 10.1002/mnfr. 201500634

Yu, W. X., Lin, C. Q., Zhao, Q., Lin, X. J., and Dong, X. L. (2017). Neuroprotection against hydrogen peroxide-induced toxicity by Dictyophora echinovolvata polysaccharide via inhibiting the mitochondria-dependent apoptotic pathway. Biomed. Pharmacother. 88, 569-573. doi: 10.1016/j.biopha.2017.01.103

Yue, Y. K., Mo, B., Zhao, J., Yu, Y. J., Liu, L., Yue, C. L., et al. (2014) Neuroprotective effect of curcumin against oxidative damage in BV-2 microglia and high intraocular pressure animal model. J. Ocul. Pharmacol. Ther. 30, 657-664. doi: 10.1089/jop.2014.0022

Zhang, H., Dai, Y., Cheng, Y., He, Y., Manyakara, Z., Duan, Y., et al. (2017a). Influence of extremely low frequency magnetic fields on $\mathrm{Ca}(2+)$ signaling and double messenger system in mice hippocampus and reversal function of procyanidins extracted from lotus seedpod. Bioelectromagnetics 38, 436-446. doi: 10.1002/bem. 22058

Zhang, M., Cui, Z., Cui, H., Wang, Y., and Zhong, C. (2017b). Astaxanthin protects astrocytes against trauma-induced apoptosis through inhibition of NKCC1 
expression via the NF-kappaB signaling pathway. BMC Neurosci. 18:42. doi: 10.1186/s12868-017-0358-Z

Zhang, M., Yan, H., Li, S., and Yang, J. (2017c). Rosmarinic acid protects rat hippocampal neurons from cerebral ischemia/reperfusion injury via the Akt/JNK3/caspase-3 signaling pathway. Brain Res. 1657, 9-15. doi: 10.1016/j. brainres.2016.11.032

Zhang, Y., Sun, D., Meng, Q., Guo, W., Chen, Q., and Zhang, Y. (2017d). Grifola frondosa polysaccharides induce breast cancer cell apoptosis via the mitochondrial-dependent apoptotic pathway. Int. J. Mol. Med. 40, 1089-1095. doi: 10.3892/ijmm.2017.3081

Zhang, L., Previn, R., Lu, L., Liao, R. F., Jin, Y., and Wang, R. K. (2018). Crocin, a natural product attenuates lipopolysaccharide-induced anxiety and depressive-like behaviors through suppressing NF-kB and NLRP3 signaling pathway. Brain Res. Bull. 142, 352-359. doi: 10.1016/j.brainresbull.2018. 08.021
Zhao, L., Wang, J. L., Liu, R., Li, X. X., Li, J. F., and Zhang, L. (2013). Neuroprotective, anti-amyloidogenic and neurotrophic effects of apigenin in an Alzheimer's disease mouse model. Molecules 18, 9949-9965. doi: 10.3390/ molecules 18089949

Conflict of Interest: The authors declare that the research was conducted in the absence of any commercial or financial relationships that could be construed as a potential conflict of interest.

Copyright (C) 2020 Cui, Lin and Liang. This is an open-access article distributed under the terms of the Creative Commons Attribution License (CC BY). The use, distribution or reproduction in other forums is permitted, provided the original author(s) and the copyright owner(s) are credited and that the original publication in this journal is cited, in accordance with accepted academic practice. No use, distribution or reproduction is permitted which does not comply with these terms. 